\title{
The Empirical Analysis about Effects of Career Decision-Making
}

\author{
Nana Ma \\ School of Management, Wuhan University of Technology, Wuhan, P.R.China \\ 1534195117@qq.com
}

\begin{abstract}
Keywords: College students;Career decidedness; Career undecidedness; Career decision-making difficulties
\end{abstract}

\begin{abstract}
Manova found that there were significantly different between career decided college students and career undecided college students both on the total level of career decision-making difficulty and 8 types of career decision-making difficulties, after controlling the democratic and naturally mature factors. But the further analysis found only lack of motivation for career decision-making, information about self and information about the career decision-making process have significant effects on the career goal-setting status. Enhancing the motivation for career decision, the knowledge about self and information about career decision- making process can significantly increase the possibility for career decided. In the end, the article discussed the result and implication for career education.
\end{abstract}

\section{Introduction}

Objective not only has guiding, motivating function, but also has the function of optimizing behavior ${ }^{[1]}$. Higher education based on the division of social specialization is a base for a completely medium education, which aims to cultivate senior specialized talents required by the society ${ }^{[2]}$. Therefore, college students self-determination of career development goals according to their own characteristics and social demands not only can help college students find new personal goals and eliminate the loss, but also can motivate them to learn consciously, make study plan based on college career and prepare well for the future into the workplace. However, many students are not able to set suitable career goals for themselves. The lack of professional goals has seriously affected the study enthusiasm and self-consciousness of college students in our country ${ }^{[3][4]}$. Although some scholars started from the perspective of the career development theory think career indecision is an normal phenomenon in one's process of career development, more scholars consider it as the need for intervention of career problems, from the theoretical explanation, the specific causes and the means of intervention have been further studied and discussed $^{[5][6]}$. In the terms of career development process, college students have experienced transition stage of career exploration and establishment after a period of long term medium education. During this period, the main tasks of development of university students are: through a variety of self-awareness and working world exploration, gradually clear career development direction, to develop specific career plan, and develop work field knowledge and skills needed to ${ }^{[7]}$. Therefore, no matter from the perspective of the development of career development or to promote students' learning power consciously, the choice and determination of career development goals is a practical problem that young college students need to solve after entering university.

In terms of the professional goal determination, there are two states: career undecidedness and career decidedness If a person has not yet determined his future career, it is called a career undecideness. If a career has been decided in the future, it is called career decidedness. In the process of determining career goals, the selection and determination of career goals is a career decision process. In this process, individuals will take impulsive, fatalistic, obedient and intuitive decision-making strategies for their own characteristics and tasks ${ }^{[8]}$. The selection and determination of career goals are important decisions in life. Therefore, the ideal decision-making method for such decisions is planned. That is, to take scientific and systematic approaches to determine career goals. To be specific, it is to experience the process of career choice, independently integrate the self knowledge and various choices, and gradually clear the direction or goal of career development. The planed decisions is a normative model of decision making that aims to help individuals become "ideal decision makers" and make appropriate and wise career decisions. 
However, what happened in the process of all kinds of difficulties(for example lack of motivation, irrational beliefs, do not understand self etc.) will have a negative effect on the individual career decision, hinder the choice and determination of personal career goals. Main purpose of this paper is to explore different types of career decision-making difficulties of college students career goals to determine the specific impact, thus for our country college students based on the actual professional development needs to carry out targeted career education, improve the ability of college students' career choice to provide empirical basis.

\section{Method}

The research sample. The methods of stratification sampling were taken from two key universities directly under the ministry of education in Wuhan (one for the liberal arts colleges and the other for polytechnic universities). Considering the freshman students have just entered the university, so there is no large freshmen into the sampling range.A total of 800 questionnaires were distributed and 721 were recovered. The recovery rate was 90.13\%.Among them, 646 questionnaires were effective and the effective recovery rate was $80.75 \%$. Males accounted for $55.73 \%$, women accounted for $43.03 \%, 1.24 \%$ did not report sex. The average age of the samples is $20.79 \pm 1.19$ years old, $36.84 \%$ in sophomore year, $37.30 \%$ in junior year, $25.08 \%$ in senior grade and $0.77 \%$ in unreported grade. According to the subjects in the"your own career goals to determine the degree" (answer options: OK, uncertain) to answer the situation, the total samples were divided into occupational orientation group and career unoriented group. Vocational orientation has 268 people, accounting for $41.49 \%$. Occupational undirected group has 372 people, accounting for $57.59 \%$. Did not answer 6 people, accounting for $0.93 \%$. Details of the study sample are shown in Table 1.

Table 1. Details of the sample $(\mathrm{N}=646)$

\begin{tabular}{|c|c|c|c|c|c|c|c|c|c|c|c|}
\hline \multirow[b]{2}{*}{ Group } & \multirow[b]{2}{*}{ Age } & \multicolumn{2}{|c|}{ Sex } & & \multicolumn{2}{|c|}{ From } & \multicolumn{3}{|c|}{ Grade } & \multicolumn{2}{|c|}{ Professional } \\
\hline & & $\begin{array}{c}\text { Ma } \\
\text { le }\end{array}$ & $\begin{array}{l}\mathrm{Fe} \\
\mathrm{ma} \\
\text { le }\end{array}$ & $\begin{array}{l}\text { large } \\
\text { and } \\
\text { mediu } \\
\text { m - } \\
\text { sized } \\
\text { cities }\end{array}$ & $\begin{array}{l}\mathrm{Sm} \\
\text { all } \\
\text { tow } \\
\mathrm{n}\end{array}$ & $\begin{array}{c}\text { Rur } \\
\text { al }\end{array}$ & $\begin{array}{l}\text { So } \\
\text { ph } \\
\text { om } \\
\text { ore }\end{array}$ & $\begin{array}{l}\text { Juni } \\
\text { or }\end{array}$ & $\begin{array}{l}\text { Seni } \\
\text { or }\end{array}$ & $\begin{array}{c}\text { Natu } \\
\text { ral } \\
\text { scie } \\
\text { nce } \\
\text { hum } \\
\text { aniti } \\
\text { es }\end{array}$ & $\begin{array}{l}\text { Social } \\
\text { scienc } \\
\text { es }\end{array}$ \\
\hline $\begin{array}{l}\text { Directio } \\
\text { nal } \\
\text { group }\end{array}$ & $\begin{array}{c}21.10 \pm 1 \\
.27\end{array}$ & 141 & $\begin{array}{c}12 \\
4\end{array}$ & 47 & 91 & 116 & 75 & 90 & 103 & 153 & 114 \\
\hline $\begin{array}{l}\text { Undefin } \\
\text { ed group }\end{array}$ & $\begin{array}{c}20.52 \pm 1 \\
.07\end{array}$ & 218 & $\begin{array}{c}15 \\
3\end{array}$ & 66 & 132 & 167 & $\begin{array}{c}16 \\
3\end{array}$ & 151 & 58 & 265 & 106 \\
\hline Total & $\begin{array}{c}20.76 \pm 1 \\
.19\end{array}$ & 359 & $\begin{array}{c}27 \\
8\end{array}$ & 113 & 223 & 283 & $\begin{array}{c}23 \\
8\end{array}$ & 241 & 161 & 418 & 220 \\
\hline
\end{tabular}

The measuring tools. Gati et al.(1996) are based on the model of ideal career decision maker. The model considers that the ideal career decision maker should be: (1) aware of the need of making career decisions and want to make such a decision; (2) able to make decisions consistent with personal goals based on scientific and systematic steps. Anyone who does not meet the ideal situation of career decision is difficult to have career decision. These difficulties affect career decision in two ways: First,hinder the decision-making process; the second is to lead decision-makers to make non-optimal decision. Gati et al. (1996) proposed a widely accepted model of a taxonomy of difficulties career decision making using a combination of experience and theory, and developed the Career Decision- making Difficulties Questionnaire $\left(\mathrm{CDDQ}^{)[9]}\right.$. The questionnaire measures the following 10 types of professional decision-making difficulties:(1) lack of motivation, the high score shows the lack of professional decision-making will;(2)indecisiveness, high score indicates that there are always difficulties in making any decision;(3)unreasonable belief, high score indicates a distorted understanding of career decisions;(4)lack of knowledge of career decision, a high score indicates know how to make a wise career 
decision;(5)lack of information about self, the high score indicates that the decision makers don't feel fully aware of themselves;(6)lack of information about occupations, a high score indicates a lack of information about a large number of occupations. (7) lack of knowledge of information acquisition methods, and high scores indicate that information about oneself and occupation is not known;(8)unreliable information, which indicates that the information that the decision maker knows is inconsistent with the information being considered;(9)internal conflict,scoring high indicates that there are conflicts and contradictions between the f- actors that are valued by individuals;(10)external conflict,high scores indicate that there are conflicts and contradictions between individual preferences of decision makers and the preferences or opinions of important people.

In 2005, Shen Xueping made a localization revision to CDDQ. The research of Shen Xueping(2005) shows that the Chinese version of CDDQ has good internal consistency, retest reliability, structural validity and validity of validity ${ }^{[10]}$. The Chinese version of CDDQ includes the above 10 types of professional decision-making difficulties, with 35 projects ( 3 of which are for identification). Considering the development of tools to measure unreasonable career beliefs ${ }^{[11]}$, this study only takes 31 projects from the Chinese version of CDDQ to measure 9 categories professional decision-making difficulties.

The data processing. Using Visual FoxPro6.0 to input and manage data, SPSS17.0 was used for statistics and analysis of data.

\section{Results}

Descriptive statistics, relevance and reliability analysis. In order to facilitate comparison, each type of professional decision-making difficulty item is added together, and then divided by the number of their own projects to the average project points for follow-up statistical analysis. The descriptive statistics, relevance and reliability analysis of each study variable are shown in table 2.

Table 2 The descriptive statistics, relevance and reliability analysis of each study variable Note: (1) * means $\mathrm{P}<.05$, ** means $\mathrm{P}<.01$; (2) diagonal bold Cronbach' $\alpha$ coefficient.

\begin{tabular}{|c|c|c|c|c|c|c|c|c|c|c|c|}
\hline variables & $\bar{M}$ & $\overline{S D}$ & 1 & 2 & 3 & 4 & 5 & 6 & 7 & 8 & 9 \\
\hline $\begin{array}{l}1 \text { lack of } \\
\text { motivation }\end{array}$ & 4.57 & 1.814 & .627 & & & & & & & & \\
\hline 2 indecisiveness & 4.99 & 1.713 & $.083^{*}$ & .624 & & & & & & & \\
\hline $\begin{array}{l}3 \text { lack of } \\
\text { knowledge of } \\
\text { career decision }\end{array}$ & 4.53 & 1.919 & $.141^{*}$ & $.382^{*}$ & .876 & & & & & & \\
\hline $\begin{array}{l}4 \text { lack of } \\
\text { information } \\
\text { about self }\end{array}$ & 3.89 & 1.727 & $.177^{*}$ & $.365^{*}$ & $.582_{*}^{*}$ & .849 & & & & & \\
\hline $\begin{array}{l}5 \text { lack of } \\
\text { information } \\
\text { about } \\
\text { occupations }\end{array}$ & 5.09 & 1.873 & $.150^{*}$ & $.333_{*}^{*}$ & $.529^{*}$ & $.547^{*}$ & .828 & & & & \\
\hline $\begin{array}{l}6 \text { lack of } \\
\text { knowledge of } \\
\text { information } \\
\text { acquisition } \\
\text { methods }\end{array}$ & 4.65 & 1.854 & $.105^{*}$ & $.375^{*}$ & $.517^{*}$ & $.554^{*}$ & $.648^{*}$ & .617 & & & \\
\hline $\begin{array}{l}7 \text { unreliable } \\
\text { information }\end{array}$ & 4.10 & 1.658 & $.152^{*}$ & $.334^{*}$ & $.390^{*}$ & $.535^{*}$ & $.423^{*}$ & $.526_{*}^{*}$ & .704 & & \\
\hline 8 internal conflict & 4.70 & 1.506 & $.188^{*}$ & $.359^{*}$ & $.367^{\circ}$ & $.423^{*}$ & $.452^{*}$ & $.459^{\circ}$ & $.563^{*}$ & .769 & \\
\hline 9 external conflict & 3.98 & 1.845 & $.153^{\circ}$ & $.178^{\circ}$ & $218^{\circ}$ & $.308^{*}$ & $.289^{\circ}$ & $.276^{\circ}$ & $.343^{\circ}$ & $.399^{\circ}$ & .734 \\
\hline $\begin{array}{l}10 \text { career } \\
\text { decidedness }\end{array}$ & 1.58 & .494 & $.274^{*}$ & $.129^{*}$ & $.302^{*}$ & $.321_{*}^{*}$ & $.239^{*}$ & $.227^{*}$ & $.247^{*}$ & $.148^{*}$ & $.128^{*}$ \\
\hline
\end{tabular}


From Table 2, there is not only obvious relationship between the various career decision-making difficulties, but also the positive relationship with the states of college students' career goals. That is, the higher level of individual career decision-making difficulties, the more difficult to determine career development goals. Among them, "lack of motivation", "lack of knowledge about career decision making process", "lack of information about self"and"lack of information about occupations"four kinds of difficulties and the states of career goals are the closest relations. At the same time, it can be seen from Table 1 that the internal consistency coefficient of 9 subscales of the career decision-making questionnaire is between 0.617 and 0.876 . With good reliability, further statistical analysis can be made.of career undefined groups in all kinds of career decision-making difficulties are higher than those of professional orientation groups.

Analysis on the differences of career decidedness and career undecidedness groups in various difficulties of career decision - making. After an effective analysis, it is clear that the scores culties, multivariate analysis of analysis(MANOVA) was used to test the differential significance. At the same time, in order to control the demographic variables and natural factors on career goals determine the effects of gender, origin, course, age and grade as concomitant variables, then carries on the multivariate analysis of variance. The results are shown in table 3.

Table 3 Multivariate analysis of variance results

\begin{tabular}{|c|c|c|c|}
\hline \multicolumn{4}{|c|}{ Multivariate Tests } \\
\hline Inspection methods & Value & \multicolumn{2}{|c|}{ The $\mathrm{F}$ value } \\
\hline Wilks’ Lambda & .859 & \multicolumn{2}{|c|}{$8.82^{* *}$} \\
\hline Hoteling's Trace & .164 & \multicolumn{2}{|c|}{$8.82^{* *}$} \\
\hline \multicolumn{4}{|c|}{ Tests of Between-Subjects Effects } \\
\hline Dimension & $\begin{array}{c}\text { Group has been } \\
\text { directed }(M \pm S D)\end{array}$ & $\begin{array}{l}\text { Pending to the } \\
\text { group }(M \pm S D)\end{array}$ & $\begin{array}{l}\text { The F } \\
\text { value }\end{array}$ \\
\hline lack of motivation & $4.05 \pm 1.84$ & $4.96 \pm 1.70$ & $22.96^{* *}$ \\
\hline indecisiveness & $4.75 \pm 1.78$ & $5.19 \pm 1.62$ & $12.78^{* *}$ \\
\hline $\begin{array}{l}\text { lack of knowledge of } \\
\text { career decision }\end{array}$ & $3.87 \pm 1.85$ & $5.04 \pm 1.82$ & $44.28^{* *}$ \\
\hline $\begin{array}{l}\text { lack of information } \\
\text { about self }\end{array}$ & $3.25 \pm 1.51$ & $4.37 \pm 1.72$ & $51.01^{* *}$ \\
\hline $\begin{array}{l}\text { lack of information } \\
\text { about occupations }\end{array}$ & $4.57 \pm 1.99$ & $5.48 \pm 1.69$ & $22.92^{* *}$ \\
\hline $\begin{array}{l}\text { lack of knowledge of } \\
\text { information } \\
\text { acquisition methods }\end{array}$ & $4.05 \pm 1.76$ & $5.09 \pm 1.80$ & $23.86^{* *}$ \\
\hline unreliable information & $3.63 \pm 1.52$ & $4.46 \pm 1.67$ & $20.48^{* *}$ \\
\hline internal conflict & $4.45 \pm 1.58$ & $4.90 \pm 1.42$ & $8.95^{* *}$ \\
\hline external conflict & $3.70 \pm 2.01$ & $4.21 \pm 1.87$ & 3.46 \\
\hline
\end{tabular}

Note: ** means $\mathrm{P}<.01$.

As can be seen from table 3, professional undetermined groups have significantly higher levels of professional decision-making difficulties than occupational orientation groups. The inter group effect test further found that, in addition to external conflicts, the undetermined group was significantly higher in the other 8 types of career decision-making difficulties than the orienting group.

Occupational goals to determine logistic regression analysis of various types of career decision making difficulties.In order to further investigate the influence of various types of career decision-making difficulties on the status of college students' career goals and find the key influenced factors to determine the career goals of college students, this study adopts Logistic regression analyses, the results are shown in table 4. 
Table 4 Occupational goals identify logistic regression analysis of difficulties in various types of career decision-making

\begin{tabular}{|c|c|c|c|c|c|}
\hline Predictor variable & B & SE & Wald & Sig & $\begin{array}{l}\text { Exp } \\
\text { (B ) }\end{array}$ \\
\hline lack of motivation & .208 & .058 & 12.727 & .000 & 1.232 \\
\hline $\begin{array}{l}\text { lack of knowledge of } \\
\text { career decision }\end{array}$ & .205 & .067 & 9.289 & .002 & 1.228 \\
\hline $\begin{array}{c}\text { lack of information } \\
\text { about self }\end{array}$ & .274 & .080 & 11.764 & .001 & 1.316 \\
\hline $\begin{array}{l}\text { The incremental } \\
\text { contribution }\left(\Delta R^{2}\right)\end{array}$ & Cox \& & Square & & $\begin{array}{l}\text { rke R } \\
.160\end{array}$ & uare \\
\hline
\end{tabular}

Note: (1)control variables are gender, source, grade, discipline and age;(2)B is non-standardized regression coefficient

It can be seen from MANOVA that although the specific difficulties of career decision-making have certain influence on the determination of college students' career goals, multivariate logistic regression analysis shows that they affect college students' career goals determine the power of all the differences. Specifically, after controlling for the relationship between each other, only a"lack of motivation","lack of information about self"and"lack of knowledge about the decision making process"three kinds of career decision-making difficulties have an obvious influence on college students' career goals.

\section{Discussion}

In recent years, several foreign longitudinal studies have found that career decidedness has not only promote individual behavioral performance, but also improve individual self-respect, life satisfaction and social adaptability ${ }^{[12][13][14]}$. College students are in the preparation of the work world, so early determination of career development goals can help them plan and prepare for their career in college. However, due to the impact of exam-oriented education, the career consciousness of college students in China is generally inadequate, and their future and career goals are uncertain. In this study sample, $57.59 \%$ of people were in an undetermined state. It can be expected that if freshmen is included in the sampling range, the proportion of college students who are not determined will be higher. Why can not young college students determine the direction of career development? Domestic and foreign scholars from the gender role, emotional emotions, self-concept, cognitive beliefs, self-efficacy, personality traits, family education and so on have extensively studied and discussed. Starting with the"ideal decision-maker model", the study explores the specific impact of career decision-making difficulties on college students' career goals, and obtains some meaningful research findings.

Firstly, all kinds of career decision-making difficulties have different influence on the career goal of college students. Multivariate Logistic regression analysis found that"lack of motivation", "lack of knowledge about the decision making process", and "lack of information about self" are the main factors influencing the selection and determination of college students' career goals. This suggests that we should focus on the above three factors when it comes to improving the career choice ability of college students in their career education. Specifically, the first step is to increase the career awareness of college students and motivate their career decisions. Motivation is the basis of behavior, but college students cannot determine career development goals without the strong motivation of career decision. The specific ways to stimulate career decision-making are campus culture, subject penetration, career curriculum and so on. The second part is to help students learn about themselves and obtain knowledge of the decision-making process through self-help activities, career courses, career groups and individual tutoring. Only after having a comprehensive understanding of themselves, students will not be lost, knowing what they want, what they can do for and what they can do. Having mastered the knowledge of career decision-making processes can help them make informed career decisions and make their own choices. 
Thirdly, although the career decision-making difficulties raised by the model of"ideal career decision maker"have significant influence on college students' career goals, the influence is not very large.As can be seen from table 3, "lack of motivation", "lack of knowledge about decision-making process"and"lack of information about myself"contribute to the incremental contribution rate of target determination of $16.00 \%$. If the other six types of decision-making difficulties were added together with the above three difficulties, the overall contribution rate could be $23.5 \%$. It can be concluded that many college students are not fully aware of their own characteristics, and then they are determined according to the scientific and systematic career decision-making process. This result is consistent with the results of the study ${ }^{[15]}$. What factors hinder college students to become"ideal decision makers", how to guide college students to take science, system of career decision-making procedures such as career choice problem is the need to further research and discussion on theory and practice.

\section{References}

[1] Yang Xiujun.Research overview of target setting theory [J].Psychological science,2004,27 (1) : 153-155

[2] Yang Deguang.Introduction to higher education[M].Shanghai:east China normal university press, 2010

[3] Chi Yanqin.Investigation and analysis of the motivation of college students[J]. Journal of Harbin institute of finance, 2009(1):59 60

[4] Hou Zhanjiao,Shi Shumeng,Zhang Jianbo.Study on the causes and countermeasures of undermotivation of college students in local universities[J].Education and career,2010(26):64-66

[5] Wu Zhiyi.Career counseling and counseling:theory and practice[M].Jiayi:Tao shi culture,2000

[6] Wang Lifen.Research on irrational beliefs, career beliefs and career decisions of university students[D].Master's dissertation, Taiwan normal university,2003

[7] Xie Baoguo,Li Dongmei.College career planning and career development[J].Beijing:Electronic industry press, 2011

[8] Dinklage L B.Decision strategies of adolescents.Unpublished doctoral dissertation.Cambridge, MA:Harvard University, 1968

[9] Gati I,Krausz M,Osipow S H.A taxonomy of difficulties in career decision making[J].Journal of Counseling Psychology, 1996,43:510-526

[10] Shen Xueping.The measurement and intervention of college students'career decision-making difficulties [D].Master's dissertation,Nanjing normal university,2005

[11]Xia Mian,Xie Baoguo.Career belief:connotation,measurement and intervention strategy[J]. Education research and experiment,2010(6):75-81

[12] Creed P,Prideaux L A,Patton Wendy.Antecedents and consequences of career decisional states in adolescence[J].Journal of Vocational Behavior,2005,67(3):397-412

[13]Earl J K,Minbashian A,Sukijjakhamin A,et al.Career decision status as a predictor of resignation behavior five years later[J].Journal of Vocational Behavior,2011,78(2):248-252

[14]Earl J K,Bright J E H.The relationship between career decision status and important work outcomes[J].Journal of Vocational Behavior,2007,71(2):233-246

[15]Zhao Bo,Ding Jing. The career orientation and management strategy of youth [J].Chinese youth research,2007(8):68-76 